\title{
The cost of pain
}

\section{Economic implications of pain management practices}

\author{
Adam Beswick, Caroline Piccininni
}

\begin{abstract}
Prescription opioid use has historically been a regular component of the management of chronic nonmalignant pain in Canada. However, the economic implications of high rates of addiction and abuse have motivated consideration of more cost-effective management strategies for chronic pain. The economic burden imposed by prescription opioid use relates in part to lost workplace productivity, increased addiction treatment program costs, and increased overall healthcare expenditure for these patients. In this article, we present research on the economic implications of the current rates of opioid prescription, and report on the specific economic advantages realized in alternative therapeutic approaches to pain management.
\end{abstract}

\section{INTRODUCTION}

Pain management is ubiquitous across diverse medical specialties, and presents a unique challenge that extends far beyond the confines of a single patient-provider interaction. Although pain management is not a new component of practice for healthcare providers, the inappropriate prescribing of opioids has played a role in the current public health crisis of the opioid epidemic. ${ }^{1}$ Therefore, increased scrutiny of the way physicians treat pain is justified within the rapidly changing landscape of pain management in Canada.

Taken from a public health perspective, pain management in Canada imposes a considerable burden on the healthcare system. Chronic pain is estimated to affect $19 \%$ of Canadians, more than half of whom report that their pain has persisted for more than 10 years. ${ }^{2}$ Many patients and physicians have turned to opioid prescriptions to manage these chronic conditions, despite the potential addictive and destructive qualities of these drugs. A recent report from the CDC demonstrated that the probability of an individual patient becoming addicted to opioid drugs can be predicted by the length of the original prescription: a one-day opioid prescription carried a $2.9 \%$ risk of long term addiction, with this number rising to $30 \%$ for patients given month-long prescriptions. ${ }^{3}$ Globally, Canadians are the second largest consumers of pharmaceutical opioids. ${ }^{4}$ In 2016, there were 19 million opioid prescriptions filled in Canada, with the greatest prevalence of use found in Ontario, where 2 million Ontarians (14\% of the population) filled opioid prescriptions in 2016.5

\section{ECONOMIC IMPACT OF OPIOID-BASED PAIN MANAGEMENT}

In addition to the personal toll opioid addiction has on patients and their families, the economic consequences of this epidemic are substantial. Informed estimates posit that up to half of the total cost of opioid misuse is directly attributable to workplace economic loss (46\%), largely driven by early death, disability, and reduced compensation due to job termination. ${ }^{6}$ Patients addicted to opioids also place a high economic burden on the criminal justice system and use 8 times the healthcare resources compared to non-addicted patients. ${ }^{6,7}$ A 2017 report by the American Federal Council of Economic Advisers estimated that the opioid crisis cost American taxpayers US $\$ 504$ billion in total economic burden in 2015, representing 2.8 percent of the gross domestic profit; ${ }^{8}$ this figure represents a 6 fold increase in total economic impact compared to previous estimates as recent as $2013 .{ }^{9}$

\section{COST-EFFECTIVENESS OF ALTERNATIVE CHRONIC PAIN MANAGEMENT STRATEGIES}

Meta-analyses of pain management with opioids have demonstrated that while opioids clearly provide strong analgesic benefit for a variety of pain etiologies (nociceptive, neuropathic, fibromyalgic, mixed), non-opioid pharmaceutical drugs can be equally as effective and, in many cases, more beneficial for patient functional outcomes. ${ }^{10}$ These differences have been attributed to the side effect profile of many opioid medications: patients have more severe side effects, higher rates of 30-day readmissions, higher costs of care, and 3.4 times greater risk of inpatient mortality. ${ }^{11}$ Similarly, one meta-analysis has shown that 'weak' opioids (eg tramadol, codeine) were not superior in cost-effectiveness to nonopioid drugs for post-operative pain management. ${ }^{11}$ Another study of post-surgical inpatients found that $13 \%$ of patients prescribed an opioid for pain management had an opioid-related adverse event; among this group of patients, the majority had a longer length of stay (55\%), higher costs of care (47\%), and an increased incidence of 30-day readmission to hospital. ${ }^{12}$ Overall, studies comparing postoperative pain management for surgical patients demonstrate that 'opioid-sparing' pain management techniques were more costeffective compared to opioid-based pain management practices. ${ }^{13}$ Injectable NSAID analgesics such as ketorolac have been shown to be equally effective for pain management, with a similar median time to achieve relief and a significantly reduced likelihood of adverse side effects and withdrawal. ${ }^{14}$

Multidisciplinary pain programs and other alternatives to pharmaceutical prescription may also have utility in the management of patients with chronic pain. For example, Kumar et al (2002) found that despite the high initial cost for spinal cord stimulation implantable devices, this technique was cost-effective in the long-term compared to opioid therapy for patients with failed 
back surgery syndrome..$^{15}$ Although many studies have shown that certain alternatives can be cost-effective in comparison to opioids, the management of pain is highly dependent on the etiology of the pain complaint. Evaluation of alternative approaches is subject to variability in inclusion criteria, drug dosages, type of pain reported, underlying etiology, and outcome criteria. There is no single analgesic medication or alternative therapeutic approach that will universally outperform opioids. It is important to recognize, however, that a variety of alternative approaches to pain exist, and that some of these methods (eg spinal cord stimulation, implantable drug delivery systems, surgical pain relief procedures) have been proven cost-effective in select patient groups. ${ }^{16}$

\section{CONCLUSION}

Physicians are uniquely responsible for making decisions that balance the need for effective pain relief with the need for judicious use of healthcare resources. This balance is difficult to manage in many opioid-based pain management treatment regimens. Indeed, the historical reliance on opioids has had negative consequences for both individual patients and the healthcare system. That being said, paid management is highly variable and dependent on a variety of patient factors; millions of Canadian patients will still depend on opioid-based pain management to treat chronic pain. Moving forward, we recommend that healthcare providers seek to supplement and, where possible, replace opioid-based management practices with more economically sustainable approaches that are based on evidence and judicious use of healthcare resources.

\section{REFERENCES}

1. Centers for Disease Control and Prevention. Physicians are a leading source of prescription opioids for the highest-risk users [Internet]. Atlanta (GA). 2014 [cited 2017 Nov 1]. Available from: https://www.cdc. gov/media/releases/2014/p0303-prescription-opioids.html

2. Schopflocher D, Taenzer P, Jovey R. The prevalence of chronic pain in Canada. Pain Res Manag. 2011;16(6):445-50.

3. Shah A, Hayes CJ, Martin BC. Characteristics of initial prescription episodes and likelihood of long-term opioid use - United States, 2006-2015. MMWR Morb Mortal Wkly Rep. 2017;66(10):265-9.

4. Canadian Institute for Health Information. Pan-Canadian trends in the prescribing of opioids, 2012 to 2016 [Internet]. Ottawa (ON): CIHI; 2017 [cited 2016 Dec 13]. Available from: https://www.cihi.ca/sites/ default/files/document/pan-canadian-trends-opioid-prescribing2017-en-web.pdf

5. Health Quality Ontario. Opioid prescribing in Ontario [Internet]. Ottawa (ON): HQI; 2016 [cited 2017 Nov 1]. Available at: http://www. hqontario.ca/System-Performance/Specialized-Reports/OpioidPrescribing

6. Birnbaum HG, White AG, Schiller M, et al. Societal costs of prescription opioid abuse, dependence, and misuse in the United States. Pain Med. 2011 Apr;12(4):657-67.

7. White AG, Birnbaum HG, Mareva MN, et al. Direct costs of opioid abuse in an insured population in the United States. J Manag Care Pharm. 2005 Jul;11(6):469-79.

8. Cohen $\mathrm{K}$. White house puts the cost of the opioid crisis at $\$ 504$ billion in 2015. Washington Examiner [Internet]. 2017 Nov 18. Available from: http://www.washingtonexaminer.com/white-house-puts-the- cost-of- the-opioid-crisis-at-504-billion-in-2015/article/2641206

9. Florence CS, Zhou C, Lou F, et al. The economic burden of prescription opioid overdose, abuse, and dependence in the United States. Med Care. 2016 Oct;54(10):901-6.

10. Kalso E, Edwards J, Moore RA, et al. Opioids in chronic noncancer pain: systematic review of efficacy and safety. Pain. 2004 Dec;112(3):372-80.

11. Furlan AD, Sandoval JA, Mailis-Gagnon A, et al. Opiods for chronic non-cancer pain: a meta-analysis of effectiveness and side effects. CMAJ. 2006 May 23;174(11):1589-94.

12. Kessler ER, Shah M, Gruschkus SK, et al. Cost and quality implication of opioid- based postsurgical pain control using administrative claims data from a large health system: Opioid-related adverse events and their impact on clinical and economic outcomes. Pharmacotherapy. 2013 Apr;33(4):383-91.

13. Philip BK, Resse PR, Burch SP. The economic impact of opioids on postoperative pain management. J Clin Anesth. 2002 Aug;14(5):35464.

14. Rainer TH, Jacobs P, Ng YC, et al. Cost effectiveness analysis of intravenous ketorolac and morphine for treating pain after limb injury: double blind randomised controlled trial. BMJ. 2000 Nov 18;321(7271):1247-51

15. Kumar K, Malik S, Demeria D. Treatment of chronic pain with spinal cord stimulation versus alternative therapies: cost-effectiveness analysis. Neurosurgery. 2002 Jul;51(1):106-15

16. Turk DC. Clinical effectiveness and cost-effectiveness of treatments for patients with chronic pain. Clin J Pain. 2002 Nov-Dec;18(6):355-65. 